\title{
Cortocircuito económico en Costa Rica durante el siglo XXI
}

Recibido: 15 de febrero 2019 Revisado: 24 de marzo 2019 Aprobado: 28 de junio 2019

Juan Manuel Retana Céspedes

Costarricense. Licenciado en finanzas y con estudios de bachillerato en Economía, Administración e Historia. Actualmente, se desempeña como docente universitario en la Ulacit e investigador en Análisis CR. Montes de Oca, San José. Correo electrónico: juan.manuel@analisiscr.com

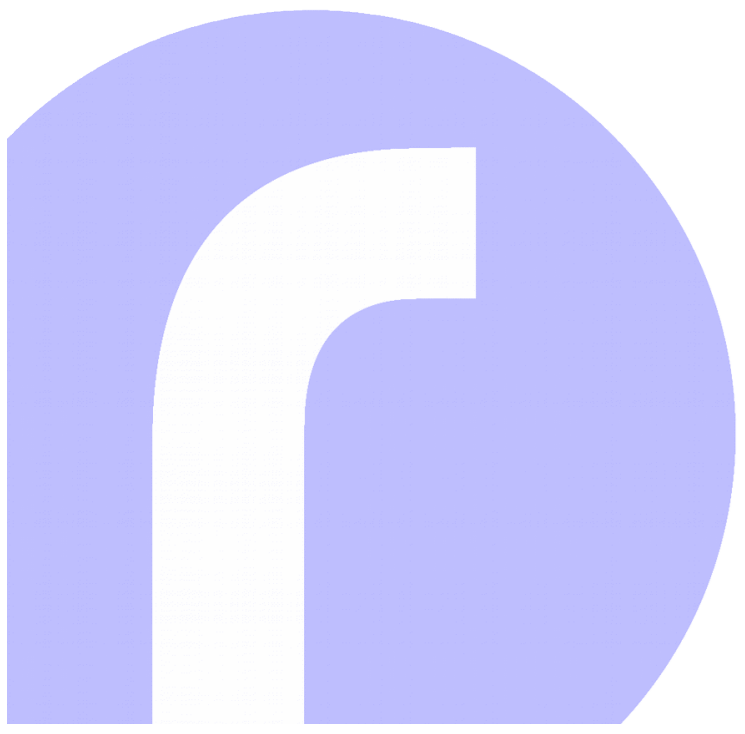

https://revistas.uned.ac.cr/index.php/rupturas/ Rev. Rupturas 10(1), Costa Rica, Ene-Jun 2020. ISSN 2215-2466. pp 45-72.
Resumen: Se analizan los principales problemas estructurales que limitan el crecimiento económico y la reducción de las desigualdades. El tema se aborda desde las redes de poder de los grupos de poder económico, los desbalances de la estructura productiva, el desempleo, el endeudamiento de las familias y el desequilibrio de las finanzas públicas. Esto a través de la narrativa de los cortocircuitos, referida a una conexión que falla y por ende el sistema empieza a funcionar mal.

Palabras clave: élites; redes de poder; neoliberalismo; desempleo; desigualdades

\section{Economic Short-circuit in Costa Rica During the Twenty-first Century}

Abstract: The main structural problems that limit the economic growth and the inequalities are analyzed. The issue is addressed from the power networks of the economic power groups, the unemployment, the indebtedness of families and the imbalance of the public finances. This through the narrative of the short-circuit, referring to a connection that fails and therefore the system starts to malfunction.

Key words: elite; networks of power; neoliberalism; unemployment; inequalities 


\section{Introducción}

La intención con este trabajo es formular un análisis del desempeño económico de Costa Rica en los últimos dieciocho años, haciendo un recorrido sobre aquellos problemas estructurales que limitan el crecimiento y amplían las desigualdades socioeconómicas. Como parte del motivo para desarrollar esta investigación, es contar con un panorama más claro y crítico sobre las raíces de algunos de los problemas que acarrea el país, tales como el aumento del desempleo, el sobrendeudamiento de la población y la desaceleración económica.

Como punto de partida, se utiliza el concepto de cortocircuito económico en referencia a la metáfora planteada por Pérez Brignoli acerca de lo que él llama "el cortocircuito de la modernidad" en América Latina, que, durante los últimos cinco siglos, se ha observado una serie de fracasos y frustraciones. Además, menciona que "La imagen del cortocircuito es suficientemente clara: un cable que se corta, una conexión que falla, y el sistema empieza a funcionar mal" $(2018,233)$.

Asimismo, para el desarrollo del análisis en torno al cortocircuito económico se abordarán cinco ejes medulares: grupos de poder económico y redes de poder, desigualdad en los sectores productivos, crecimiento económico y desempleo, endeudamiento de la población y déficit fiscal.

El artículo se divide en dos secciones, la primera contextualiza la política económica desde la óptica de las redes de poder de grupos empresariales importantes y sectores relacionados a los think tanks, y de cómo estos han influido en la hegemonía del pensamiento económico a través del posicionamiento de figuras clave en los gabinetes. Por ello se realiza una aproximación sobre cómo esto ha coartado el crecimiento económico y la reducción de las desigualdades. Además, se emplea información de la Superintendencia General de Entidades Financieras (SUGEF), el Banco Central de Costa Rica (BCCR), estudios previos y páginas web de organizaciones, instituciones públicas y empresas.

La segunda sección tiene como objetivo analizar los problemas estructurales que afronta la economía en la actualidad, haciendo hincapié en que su gestación proviene de al menos dos décadas atrás. Como parte del análisis, se utilizan estadísticas del BCCR, el Instituto Nacional de Estadísticas y Censos (INEC) y la Secretaría Ejecutiva del Consejo Monetario Centroamericano (SECMCA). Esto con el fin de estructurar una base para el estudio de las complicaciones económicas y la eventual formulación de propuestas alternativas para hacerles frente. 


\section{Aspectos metodológicos}

La temporalidad del estudio se enfoca en el análisis de estadísticas económicas a lo largo del siglo XXI para evaluar el desempeño que ha tenido el país en esta materia. Sin embargo, a manera de contexto, se parte del Proyecto Histórico Neoliberal (PHN) iniciado en 1984 y que continúa hasta la actualidad, el cual define los principales rasgos dominantes y evolución del desarrollo de Costa Rica, contemplando los procesos políticos y singularidades económicas (Vargas Solís 2015). Este autor caracteriza el PHN en tres fases ${ }^{1}$ que han marcado los cambios en las políticas económicas del país. En el caso del presente artículo, se trabaja sobre las dos últimas fases, pero principalmente en la tercera, la cual comprende los últimos trece años.

Como parte del análisis para determinar las redes de poder y vinculaciones con gabinetes, se utiliza la metodología de prosopografía para caracterizar a un grupo de personas a través del estudio de sus vidas de forma colectiva (biografías colectivas) y sus relaciones profesionales (Ferrari 2010). De igual manera, se usan reportes de instituciones públicas, investigaciones anteriores relacionadas con grupos empresariales y tanques de pensamiento, se consultan sitios web de empresas e instituciones y una publicación oficial sobre los primeros cien años de Florida Ice \& Farm. Estas fuentes permiten realizar asociaciones familiares, corporativas, profesionales y políticas.

Dos definiciones generales, la primera sobre el concepto de política económica, refiriéndose a que las relaciones económicas forman parte de las relaciones sociales y que se pueden describir según lo que tiene en común con otras políticas públicas, la forma como actúan sobre las estructuras económicas (producción y distribución) y su proyección temporal de corto, mediano y largo plazo (Vargas Solís 2005). La segunda sobre los tanques de pensamiento (think tanks), los cuales están conformados por equipos económicos, comunidades epistémicas y conjunto de asesores vinculados con el sector de grupos empresariales (Blanco Lizano 2010).

El análisis cuantitativo de la información estadística de fuentes oficiales provenientes de instituciones públicas se realizó mediante Microsoft Excel. Esto para graficar, crear tablas y procesar datos que permitan conceptualizar mejor el desempeño de variables económicas y realizar comparaciones a lo largo de los años.

\section{Contextualización de la política económica: grupos de poder y pensamiento hegemónico}

Como parte del análisis de las problemáticas que enfrenta la economía costarricense, es menester tomar en cuenta las redes de poder que existen en torno a las políticas económicas, que se ven ejecutadas, más específicamente, a través de las instituciones tales como el Ministerio de Hacienda, el BCCR, el Ministerio de Economía, Industria y Comercio (MEIC) y el Ministerio de Comercio Exterior (COMEX). Como consecuencia, se estudian los aportes, tanto teóricos como empíricos acerca de estos temas en el país.
1. La primera es la exportación ligera que va de 1984 a 1997 la segunda es el auge transnacional entre 1998 y 2004, y la tercera fase es la del aumento de flujos de capital financiero y transnacional a partir de 2005 hasta la actualidad. 
Así mismo, Blanco Lizano ha realizado investigaciones que analizan las redes existentes entre grupos y asociaciones que se enfocan en crear "núcleos de interés" para el intercambio de información y recursos. Para ello, utiliza aportes de Pierre Bourdieu en la teoría de los campos, en el cual menciona que, para comprenderlo "Bourdieu propone el estudio de dos aspectos determinantes: capitales y habitus poseídos por los agentes presentes en los campos, por un lado, y por otro, estrategias de conservación y subversión del campo en estudio desarrolladas por los agentes" (Blanco Lizano 2012).

La cita anterior hace referencia a los conceptos de capitales y habitus. El primero relacionado con el trabajo acumulado que se presenta en tres formas diferentes: capital económico, cultural y social, los cuales se explican bajo el entendimiento de cómo la institucionalidad les percibe, es decir, en dinero y derechos de propiedad, títulos académicos y títulos nobiliarios, respectivamente. Por otro lado, el habitus se puede entender como saberes, conocimientos y experiencias aprendidas socialmente y que dan a las personas diferentes habilidades para ciertos campos y áreas de desempeño (Blanco Lizano 2012). Por ejemplo, para el caso costarricense el autor menciona que:

En el escenario social y en los escenarios del poder ejecutivo y legislativo, los agentes aparecen como idénticos ante la ley; y donde el agente dominante es una mezcla de intereses públicos y privados que han conciliado sus capitales y habitus para reclamar y autorreferenciarse como los auténticos representantes del interés general y únicos capacitados para producir políticas de fomento a las exportaciones en Costa Rica (Blanco Lizano 2012, 100).

Es decir, esa conciliación entre los capitales y habitus ha permitido la elaboración de políticas públicas de fomento en la diversificación de exportaciones desde la década de los ochenta, caracterizándose por redes corporativas (sector empresarial) que tienen presencia en puestos clave dentro del gobierno, participación en juntas directivas de la banca estatal, financiamiento de partidos políticos y vinculaciones con tanques de pensamiento que les ha posibilitado autorreferenciarse y dirigir la política económica.

En relación con lo anterior, otro concepto importante para los análisis de redes de poder es el de imbricación, el cual establece que para el estudio de las relaciones económicas es primordial partir del hecho que estas se encuentran entrelazadas con otras estructuras y procesos sociales (redes interpersonales en la que las personas están inmersas), siendo imposible su separación en el análisis económico. Es decir, "que las acciones económicas se encuentran imbricadas en la estructura social" (Pozas Garza, Mora Salas y Pérez Sáinz 2004, citado en Blanco Lizano 2012). 
En cuanto a los aportes empíricos sobre redes de poder, existen hallazgos relacionados con la presencia de actores corporativos (sectores empresariales y tanques de pensamiento) dentro de la formación de gabinetes y partidos políticos que buscan respaldar sus intereses sectoriales para elaborar políticas públicas (económicas y exportadoras) en Costa Rica, además, en muchos casos estas terminan siendo decididas bajo la mampara de presiones por parte de organismos internacionales. Este aporte analiza los vínculos entre los cargos públicos del sector exportador con las organizaciones Coalición Costarricense de Iniciativas de Desarrollo (CINDE) y la Academia de Centroamérica y Consejeros Económicos y Financieros S. A. (CEFSA) entre 1986 y 2014 (Blanco Lizano 2010), así como alerta sobre lo siguiente:

El peligro fundamental de tales reduccionismos (de la democracia) es la elitización y oligarquización de las decisiones por grupos corporativos, que controlando las estructuras de selección de los partidos políticos y donde solo se autorreferencian ante ellos mismos, sin que existan mecanismos de control social, jurídico y político que les exija, enjuicie y controle por sus actuaciones; pueden terminar convirtiéndose en el principal obstáculo para procesos efectivos de profundización de la vida democrática en Costa Rica (Blanco Lizano 2010, 170).

Lo anterior se vislumbra en los incentivos que tienen los sectores empresariales y tanques de pensamiento a la hora de emprender sus cabildeos con las autoridades de gobierno, se centran en la búsqueda de "rentas políticas" (rentismo), siendo estas entendidas como privilegios en medidas económicas (por ejemplo: tipo de cambio e impuestos diferenciados) para ampliar y proteger sus intereses (Blanco Lizano 2010).

Los grandes grupos empresariales, controlados por familias, tienden a utilizar sus redes de influencia política para favorecer su riqueza, mediante derechos de propiedad, instituciones ineficientes y otras que se mencionarán más adelante. Dichas prácticas fomentan el dominio de estos grupos, al mismo tiempo que obstaculizan las oportunidades de crecimiento económico y consolidan un "capitalismo oligárquico", "capitalismo de relaciones" o "capitalismo jerárquico" (Bull y Kasahara 2017).

El estudio de las élites empresariales en Costa Rica es parte medular para entender el desempeño económico que ha tenido el país, y por ende evaluar la eficacia de las políticas ejecutadas en esta área. Por ello es conveniente, referirse a que el término élite se usa para caracterizar al grupo que controla el capital y los medios de producción, es decir, las clases dominantes que ac- 
túan en estrecha alianza entre sí, aquellas vinculadas y con influencia en los sectores político, económico e internacional (Bull y Kasahara 2017).

Grupos de individuos que, debido a sus recursos económicos, pericia/conocimientos, conexiones o posición en organizaciones políticas o de otra índole, mantienen una posición privilegiada para influir de manera formal o informal en decisiones o prácticas de importancia general (Bull y Kasahara 2017, 41).

Además, el estudio de las élites empresariales es de relevancia para contextualizar la evolución económica de Costa Rica y su relación con el proceso de globalización de los últimos cuarenta años. Vargas Solís (2005) menciona que los "mecanismos de determinación-condicionamiento" impactan la economía costarricense (pequeña y subdesarrollada), esto porque las políticas económicas son decididas bajo el dominio de los grupos hegemónicos, quienes tienen el acceso a los principales flujos de capital y medios de producción decisivos.

Un claro ejemplo de lo anterior es el manejo de la deuda pública, los inversionistas que la compran y el ajuste fiscal que se aprueba en Costa Rica a finales del 2018. Las agencias calificadoras, los centros de estudios y empresas asesoras ponen su criterio sobre cuál es el problema del país y dónde se debe atacar (políticas de austeridad principalmente), así mismo, los organismos internacionales (Fondo Monetario Internacional y Banco Mundial) están pendientes sobre estos criterios técnicos y cuánta deuda nueva se va a emitir, lo que desean es que el país les "dé tranquilidad" y demuestren que están tomando el camino "correcto". Para lograrlo, son clave los puestos en el Ministerio de Hacienda y el Banco Central, lo cual se comentará más adelante.

El neoliberalismo es una corriente de pensamiento que inicia en los años treinta del siglo XX, se basa en la vieja política del laissez faire del liberalismo clásico, y su nombre se acuñó después de la conferencia internacional llamada el "Coloquio Lippmann", la cual buscaba dejar en firme la importancia de la economía de mercado, el Estado de derecho y las libertades individuales y económicas como garantía del bienestar y la libertad. Asimismo, en la década de los cuarenta se funda la Sociedad del Mont-Pèlerin a la cabeza del economista austriaco Friedrich Hayek. Este centro de pensamiento ha tenido la tarea de propagar las ideas neoliberales en las principales escuelas de economía del mundo y que, para la década de los setenta, habían surgido figuras importantes como Milton Friedman, quien tuvo gran influencia en la Universidad de Chicago. Además, en el plano de la política pública, fueron Margaret Thatcher, en Gran Bretaña, y Ronald Reagan, en los Estados Unidos, quienes llevaron a cabo reformas neoliberales a nivel local y global (Escalante Gonzalbo 2015). 
Uno de los puntos en debate es sobre la hegemonía del pensamiento económico, ya que, en los últimos cuarenta años, gran parte de los economistas profesan las mismas ideas en torno al neoliberalismo. Escalante Gonzalbo sostiene que los profesionales con esta inclinación ideológica tienen un profundo convencimiento de la hipótesis de los mercados eficientes, la cual es una entre muchas herramientas que conforman la "nueva macroeconomía clásica". Además, que, para explicar este arraigo, hace referencia a la disonancia cognitiva, la cual ocurre cuando una persona cree fuertemente en algo y, aunque se le muestren pruebas sustentadas de su equivocación (disonancia incómoda), tiende a reafirmar su creencia con más firmeza. También existe otro motivo importante para defender esta hipótesis: el hecho de respaldar su profesión, esto porque se pone en tela de duda toda la institución en la cual se han formado, publicado e incluso ensañado, prácticamente pone en riesgo su carrera, nombre y honorarios profesionales (Escalante Gonzalbo 2015).

Los economistas más influyentes, y los departamentos de economía más influyentes, forman parte de un circuito de empresas de consultoría, agencias de evaluación, burocracias públicas y privadas dominadas por el dinero de los grandes bancos, y de las principales corporaciones empresariales. Se antoja difícil imaginar que los sueldos que reciben no influyan en absoluto sobre su trabajo, y que lo que enseñan en clase y lo que descubren en sus modelos, y lo que recomiendan a los legisladores, no tengan nada que ver con los intereses de quienes están financiando todo ello (Escalante Gonzalbo 2015, 225).

Lo anterior pone la alarma sobre las relaciones de poder e intereses sectoriales con la producción de ideas que generan los centros de estudio (think tanks), fundaciones, empresas asesoras, intelectuales, periodistas y políticos que están vinculados con las grandes corporaciones. Para el presente artículo, se toman en cuenta esta clase de organizaciones en Costa Rica, y que durante las últimas cuatro décadas han sido mentoras, creadoras de opinión e ideólogas del Proyecto Histórico Neoliberal.

Para el análisis de este artículo, se toma como base la conceptualización que realizó Robles Rivera sobre los grupos de poder económico (GPE), conocidos porque su peso económico se traduce en peso político y que, además, trabajan como grupos empresariales interrelacionados. Así mismo, se hace referencia a que los GPE son parte de los sectores ganadores del "neoliberalismo a cuentagotas", el cual incluye una paulatina privatización y alianzas 
2. La investigación de Robles Rivera del 2016 incluye un cuadro comparativo de GPE, el cual detalla información tal como empresas asociadas, año de fundación, principales familias y sectores en los que operan. Esto facilitó la vinculación de nombres, empresas y puestos en los gabinetes. público-privadas que han caracterizado las relaciones entre estos y el gobierno de turno en los últimos años (Robles Rivera 2016).

En total, Robles Rivera analiza cincuenta y tres GPE con las siguientes características: 1) la mayoría iniciaron a partir de 1950, solamente el $23 \%$ (12 del total) se fundaron en décadas anteriores; 2) una parte representa el antiguo modelo agroexportador conformado por la "base económica oligárquica tradicional"; 3) a partir de los años cincuenta surge una nueva fracción industrial impulsada por el modelo de sustitución de importaciones; 4) a finales del siglo XX y principios del $X X I$ se consolidan otros actores en torno al capital transnacional y financiero; 5) los GPE se organizan en 10 diferentes sectores (finanzas, automotriz, construcción, comercial, alimenticio, construcción, comunicación, servicios, industria e inmobiliario); 6) solo dos de los GPE son presididos por mujeres (Roble Rivera 2016).

Los GPE conforman conglomerados de empresas diversificadas (cuatro o cinco sectores), de capital nacional, que tienen un gobierno corporativo de control jerárquico familiar con vínculos en participaciones accionarias y conexiones financieras (Robles Rivera 2014). En el caso de este trabajo, se toman en consideración aquellos grupos que poseen relaciones con puestos políticos en el sector económico, centros de investigación y empresas asesoras.

Por otro lado, el desarrollo de América Latina en torno a la combinación de sistemas mayormente presidencialistas y con legislaturas pluralistas son complementarios a la hegemonía de los grandes grupos empresariales, esto por la gran cantidad de caminos de influencia en los procesos de negociación entre presidentes, legisladores y otras ramas del gobierno (Bull, Castellaci y Kasahara 2014).

Como parte de las redes de influencia, es frecuente encontrar que los propietarios de GPE financien contiendas políticas (Rodolfo Jiménez Borbón con Abel Pacheco, Oscar Arias (2006) y Laura Chinchilla) y tomen puestos en campañas (Alfredo Ortuño Victory, de Grupo Improsa, fue tesorero en la campaña de Oscar Arias en el 2006). Esto con el fin de disfrutar de un privilegiado acceso a personas clave dentro de los gobiernos para avanzar con sus agendas (Bull, Castellaci y Kasahara 2014). Para ilustrar este tipo de relaciones y redes de influencia, seguidamente, se presenta un diagrama con información sobre sectores con núcleos de interés.

Primeramente, se analizaron los cincuenta y tres GPE que sistematizó Roble Rivera, buscando alguna vinculación con puestos en los gabinetes de los último dieciocho años ${ }^{2}$; además, se incluyeron organizaciones del sector de tanques de pensamiento, partiendo de la lista iniciada por Blanco Lizano.

Para determinar los vínculos entre los sectores y gabinetes, las publicaciones de reportes por parte de las instituciones públicas se toman como partida para tener una lista de jerarcas de dichas instituciones. Los programas macroeconómicos del Banco Central (que se publican todos los años), incluyen los nombres de la junta directiva de la institución al momento de su publicación, y en donde el ministro o ministra de Hacienda tiene un puesto (BCCR 
2019). También, el MEIC cuenta con una lista de exjerarcas en su sitio web (MEIC 2015). Para los casos del Banco de Costa Rica y el Banco Nacional, se utilizó la información de la página web de la Superintendencia General de Entidades Financieras, donde publica la información referente a los miembros de juntas directivas y gerentes (SUGEF 2016).

\section{Diagrama 1. Relación entre GPE, tanques de pensamiento y conformación de gabinetes}

\begin{tabular}{|c|ll|}
\hline \multicolumn{2}{|c|}{ Sectores } & \multicolumn{2}{l}{} \\
\cline { 1 - 2 } & - Florida Ice \& Farm & - Grupo Aldesa \\
& - Grupo Cuestamoras & - Grupo SAMA \\
Empresarial & - Grupo Constenla & - Grupo Esqui Vol \\
Grupos de Poder & - Grupo Nación & - Grupo EI Viejo \\
Económico & - Grupo Intaco & - Grupo Comeca \\
& - Grupo Montecristo & - Corporación BCT \\
& - Grupo Taboga & - Grupo Financiero Improsa \\
& - Corp. Auto Mercado & - Grupo Financiero Cathay \\
& - Grupo Garnier & \\
\hline \multirow{3}{*}{ Tanques de pensamiento } & Asociación la Academia de Centroamérica, Consejeros \\
Centros de estudio y & Económicos y Financieros S.A. (Cefsa), Ecoanálisis, \\
asesores & Instituto Centroamericano de Administración de \\
& Empresas (Incae), Mesoamérica Investments y Deloitte \& \\
\hline
\end{tabular}

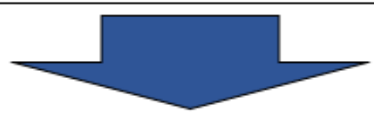

Puestos en ministerios, viceministerios, presidencias y direcciones (2000-2018)

\begin{tabular}{|c|c|c|}
\hline Ministerio de Hacienda & Banco Central & $\begin{array}{l}\text { Ministerio de Economia, } \\
\text { Industria y Comercio }\end{array}$ \\
\hline $\begin{array}{l}\text { Leonel Baruch Goldberg } \\
\text { Federico Carrillo Zurcher } \\
\text { Alberto Dent Zeledón } \\
\text { Edna Camacho Mejía } \\
\text { Jorge Walter Bolaños } \\
\text { Rocío Aguilar Montoya }\end{array}$ & $\begin{array}{l}\text { Eduardo Lizano Fait } \\
\text { José Rafael Brenes Vega } \\
\text { Francisco de Paula Gutiérrez } \\
\text { Luis Mesalles Jorba } \\
\text { Rodrigo Bolaños Zamora } \\
\text { Rodrigo Cubero Brealey }\end{array}$ & $\begin{array}{l}\text { Tomás Dueñas Leiva } \\
\text { Vilma Villalobos Carvajal } \\
\text { Alfredo Volio Pérez } \\
\text { Samuel Guzowski Rose }\end{array}$ \\
\hline $\begin{array}{c}\text { Ministerio de Comercio } \\
\text { Exterior }\end{array}$ & Banco de Costa Rica & Banco Nacional \\
\hline $\begin{array}{l}\text { Alberto Trejos Zúñiga } \\
\text { Anabel González } \\
\text { Campabadal } \\
\text { Marco Ruiz Gutiérrez }\end{array}$ & $\begin{array}{l}\text { Alberto Raven Odio } \\
\text { Danilo Montero Rodríguez } \\
\text { Mario Esquivel Volio } \\
\text { Mauricio Jenkins Coronas } \\
\text { Víctor Herrera Arauz } \\
\text { Marta Arrea Brenes }\end{array}$ & $\begin{array}{l}\text { Alfonso Guardia Mora } \\
\text { Alfredo Volio Pérez } \\
\text { José Jenkins Rodríguez } \\
\text { Ricardo Monge González } \\
\text { Fernando Naranjo Villalobos }\end{array}$ \\
\hline
\end{tabular}

Fuente: elaboración propia con base en Robles Rivera (2016), Blanco Lizano (2010), la Superintendencia General de Entidades Financieras, Programas Macroeconómicos del Banco Central y páginas web de las instituciones y organizaciones. 
Solo se incluyen aquellos GPE en los cuales se confirma cierta vinculación con los gabinetes del periodo estudiado, sin embargo, es muy probable que queden por fuera algunos de los grupos empresariales que están constituidos por sociedades anónimas y empresas tenedoras de acciones (holdings), porque su rastreo se vuelve más difícil, siendo esto una limitante dentro de la investigación.

Por el lado de los tanques de pensamiento, se utiliza la información de las páginas web de cada institución, en donde publican los nombres de sus socios, asociados (Academia de Centroamérica 2019) y equipo de trabajo (CEFSA 2013). Estas dos ya habían sido incluidas en el trabajo de Blanco Lizano (2010). Además, en este caso, se incluye la empresa consultora Ecoanálisis, la cual fue fundada en 1995 y sus socios están directamente vinculados con puestos políticos, tal es el caso de Édgar Robles Cordero (ex superintendente de pensiones), José Rafael Brenes Vega, Luis Mesalles Jorba, Miguel Ángel Rodríguez Echeverría, Ricardo Monge González, entre otros (Ecoanálisis 2019).

También, se incluyó a un banco de inversión (Mesoamerica Investments 2019) que ha asesorado a gran cantidad de empresas en la región centroamericana, y cuyo socio fundador es considerado uno de los asesores de grupos empresariales más influyentes de la región desde los años noventa (Strachan 2017). Además, han apoyado a GPE en la ruta por la diversificación de negocios y la internacionalización de sus operaciones (Bull y Kasahara 2017).

Del mismo modo, se incluye al INCAE como un actor importante en las redes de poder, este se establece en Costa Rica a partir de 1982 (ya se había fundado en Nicaragua en los sesenta), en 1989 inicia el "Programa de Entrenamiento de Líderes Políticos", el cual se ha caracterizado por formar a cientos de profesionales pertenecientes a grandes grupos empresariales de la región, mediante programas de administración de negocios, estrategia empresarial, finanzas, economía, entre otros (INCAE 2013). También, profesores y decanos han estado vinculados con puestos políticos y empresas asesoras (Francisco de Paula Gutiérrez y Alberto Trejos Zúñiga).

Finalmente, se incorpora a Deloitte \& Touche S.A. por su vinculación con puestos políticos y porque asesora (auditoría externa, impuestos y consultoría estratégica) a GPE en la región. La actual ministra de Hacienda laboraba (hasta el 2018) como socia del área de Servicios Financieros e Infraestructura en esta firma (CONASSIF 2018). Así mismo, dos de sus actuales socios (Alan Saborío y Francisco Villalobos) han ocupado el puesto de director general de Tributación Directa del Ministerio de Hacienda en años pasados (Deloitte 2019).

El Banco Central y el Ministerio de Hacienda son los que más puestos vinculados tienen con los sectores empresariales y de tanques de pensamiento. La mayoría de las personas que ha ocupado cargos tienen formación en economía, entre los más conocidos son Eduardo Lizano, Francisco de Paula Gutiérrez y Rodrigo Bolaños, los tres con doctorados en economía de universi- 
dades internacionales. El último fue exalumno de Milton Friedman (Hidalgo Bogantes 2013) en la Universidad de Chicago ("Chicago Boy"). El actual presidente del Banco Central, es un ex alto jerarca del Fondo Monetario Internacional (Leitón y Ramírez 2018). Estos distinguidos economistas están vinculados por medio de la Academia de Centroamérica y CEFSA.

CEFSA también están vinculada con otras figuras importantes mencionadas en el diagrama 1. Alberto Trejos, profesor del INCAE, exministro de COMEX y vicepresidente de la junta directiva de Grupo Cuestamoras (Cuestamoras 2019). Asimismo, Luis Liberman Ginsburg (ex vicepresidente de la República entre 2010 y 2014), Fernando Naranjo (ex ministro de Hacienda y exgerente del Banco Nacional), Félix Delgado Quesada (exgerente del Banco Central) y José Luis Arce Durán que fungió como presidente y director del Consejo Nacional de Supervisión del Sistema Financiero (CEFSA 2013).

Como se puede apreciar, las direcciones de política económica (al menos la fiscal y monetaria) han estado acaparadas por un círculo muy pequeño de profesionales que tienen fuertes vínculos con los GPE. Como lo menciona Vargas Solís (2015), existe una corriente hegemónica de la economía, más específicamente en la teoría económica neoclásica que ha sido la base del Proyecto Histórico Neoliberal en Costa Rica.

Como se menciona anteriormente, para los GPE es de suma importancia conseguir acceso privilegiado de personas claves dentro de los gobiernos, por ello es necesario poner atención a este tema:

También las nociones de redes de poder, redes de información y mallas de poder, acercan las lógicas analíticas foucaultianas a las de los analistas de redes de poder, interesa conocer la integración y composición de tales redes, sus integrantes, los mecanismos que le dan consistencia a las [sic] redes en el tiempo, cómo se articulan en el espacio, quiénes y cómo [sic] monopolizan los recursos de poder, entender las formas concretas en que las instituciones estatales resultan espacios privilegiados de ejercicios del poder, tal como también lo señalaba Bourdieu de la necesidad de administrar esa especie de metacapital que es el capital estatal (Blanco Lizano 2012, 103).

Lo anterior nos dirige hacia cómo el capital estatal es administrado a través de puestos clave en los gobiernos de turno, las vinculaciones con juntas directivas de bancos estatales y mediante la promoción de ideas (think tanks). Esto posibilita que los GPE tengan inherencia y control más allá de los me- 
dios de producción, ya que también lo hacen en la dirección de políticas económicas como se ha mencionado anteriormente.

De igual manera, miembros de las juntas directivas de Grupo Nación y Florida Ice \& Farm (FIFCO) han financiado campañas políticas e incluso formado parte del gabinete, por ejemplo, la economista Edna Camacho, quien, según datos oficiales de FIFCO (Porras Jara 2010), ingresó a la junta como fiscal desde el 2005 (actualmente ex Ministra de Coordinación Económica) y que también está vinculada con la Academia de Centroamérica, de la cual fue presidenta entre 2002-2003 y 2013-2017 (Academia de Centroamérica 2019). Además, tiene relación con Grupo Aldesa, de donde su esposo es presidente (Aldesa 2019). Igualmente, Guillermo Alonso Guzmán (presidente de Corporación Auto Mercado) pertenece a la junta directiva de FIFCO desde 1991, y ocupa los puestos de fiscal y vocal a partir de 2007 (Porras Jara 2010).

Otro actor relevante es Corporación BCT, pues dos de sus socios han ocupado cargos importantes en gobiernos pasado. Leonel Baruch (actual propietario de Crhoy.com) como ministro de Hacienda en la presidencia de Miguel Ángel Rodríguez, y Antonio Burgués Terán, nombrado embajador de la República Popular de China en la segunda administración Arias Sánchez (Robles Rivera 2014).

Los vínculos siguen: Jorge Walter Bolaños y el Grupo Financiero Cathay, Tomás Dueñas Leiva y Grupo INTACO, Luis Mesalles Jorba y Grupo Comeca, Fernando Naranjo Villalobos con Grupo Improsa, entre otros. También, el sector financiero ha tenido su presencia, tal y como se menciona a continuación:

La importancia fundamental de los lazos políticos, el posicionamiento de figuras clave y cercanas al capital financiero privado en los órganos de regulación, así como a la cabeza de los bancos públicos, radica en tener privilegiado acceso a la información y, sobre todo, a frescos recursos económicos para nuevas inversiones a niveles nacionales o regionales, sin la dependencia del capital financiero regional o transnacional. Esto también podría implicar procesos de "privatización suave desde adentro", los cuales permitirían favorecer desde lo público los intereses de la banca privada y así socavar la posición privilegiada de la banca pública costarricense (Robles Rivera 2014, 50). 
Esta cita se relaciona con lo que se puede observar en el diagrama 1, ya que accionistas y directivos del sector bancario y bursátil privado (Corporación BCT, Grupo Financiero Cathay, Banco Improsa y Grupo Aldesa) han tenido posiciones privilegiadas en la toma de decisiones mediante las juntas directivas en bancos estatales, puestos en el Ministerio de Hacienda y entidades reguladoras (SUGEF y CONASSIF).

Aquí es donde se vislumbra el primer cortocircuito que está enfrentando la economía costarricense, el cual se relaciona con la hegemonía el pensamiento económico y, por ende, la generación de ideas y propuestas en torno a los problemas nacionales, porque la perspectiva del análisis acerca de estos ha sido acaparada por un grupo de profesionales vinculados con los GPE y empresas asesoras que han moldeado las políticas económicas del neoliberalismo a la tica y han reducido el espacio para propuestas alternativas.

Los lazos políticos y el posicionamiento de figuras cercanas a los sectores empresariales y tanques de pensamiento han cerrado el debate de las ideas, ya que estas se han configurado sobre la base del libre mercado en la globalización financiera-especulativa, la transnacionalización de la producción y el antiestatismo (Vargas Solís 2006). Las políticas aplicadas en los últimos cuarenta años tienen un contenido de privatización (banca, seguros, telecomunicaciones, educación, salud, etc.) y un enfoque en apoyar el sector exportador y transnacional (inversión extranjera directa), por encima del fomento de la economía local; una reforma fiscal recién aprobada, que protege los intereses de los GPE, por su falta de cambio en el impuesto sobre la renta, que no incorpora la renta mundial, la renta global queda a medias y no se añaden las recomendaciones de la Organización para la Cooperación y el Desarrollo Económico (OCDE) sobre el tratamiento de la evasión y elusión fiscal.

Para avanzar en la solución de problemas económicos, es menester generar un relevo de figuras clave en los puestos económicos, de manera que se eviten vinculaciones directas con GPE, teniendo mayor rigurosidad a la hora de seleccionar miembros de juntas directivas y de gabinetes. Asimismo, se torna urgente agregar nuevas ideas desvinculadas a la Academia de Centroamérica, CEFSA, INCAE y Ecoanálisis, en donde se pueda incorporar un mayor entendimiento de las realidades socioeconómicas y políticas de los países latinoamericanos y que se dé paso a ideas alternativas o heterodoxas.

Finalmente, se considera relevante tener claro el enfoque del análisis de las complicaciones económicas que enfrenta el país, pues las propuestas y reformas que están avanzando en los últimos meses conducen (y con mayor fuerza) hacia la misma línea de acción de los últimos cuarenta años, en que se abordan por la vía de la austeridad fiscal (señalando el gasto público como malo), el control de la inflación (inflation targets) y simplificación de trámites. Sin embargo, se está manteniendo en segundo plano la aceleración económica y la reducción del desempleo y las desigualdades; temas que se abordarán en la siguiente sección. 


\section{Análisis de los problemas estructurales y sus limitantes para la economía costarricense}

En el análisis de los problemas económicos que enfrenta un país, estos pueden abordarse desde diferentes ópticas a la hora de priorizarlos y ponderar su eventual afectación para el crecimiento económico y desarrollo humano. En este trabajo, dichas problemáticas se tratarán desde las desigualdades, principalmente en el aparato productivo, el empleo y la sociedad en general.

Como primer punto, se estudia la evolución del sector real (bienes, servicios y factores de producción) que, de acuerdo con datos del producto interno bruto (base 2012), la economía costarricense ha crecido en promedio por año un 4.0\% durante los últimos dieciocho años. Además, si el dato lo separamos en dos periodos, entre el 2000 y 2007, este promedio fue de $4.9 \%$, mientras que entre el 2008 y 2018 fue de $3.3 \%$. Cabe destacar que el último periodo incluye el efecto de la crisis financiera internacional de 2008 . No obstante, desde el año 2016, la economía viene enfrentando una desaceleración que está presionando la tasa de desempleo y que muestra disparidades entre industrias.

Tabla 1. PIB a precios constantes por actividad económica (año de referencia 2012)

\begin{tabular}{|c|c|c|c|c|c|c|c|c|}
\hline & \multicolumn{2}{|c|}{$\begin{array}{c}\text { Composición } \\
\text { porcentual }\end{array}$} & \multicolumn{3}{|c|}{$\begin{array}{l}\text { Tasa de crecimiento } \\
\text { anual compuesta }\end{array}$} & \multicolumn{3}{|c|}{$\begin{array}{l}\text { Variación interanual (2000- } \\
\text { 2018) }\end{array}$} \\
\hline & 2000 & 2018 & $\begin{array}{l}2000- \\
2018\end{array}$ & $\begin{array}{l}2000- \\
2007\end{array}$ & $\begin{array}{l}2008- \\
2018\end{array}$ & Máximo & Mínimo & Tend \\
\hline Agricultura, silvicultura y pesca (ASP) & $7,4 \%$ & $5,1 \%$ & $2,1 \%$ & $3,3 \%$ & $1,8 \%$ & $9,1 \%$ & $-3,4 \%$ & \\
\hline Minas y Canteras (MC) & $0,5 \%$ & $0,3 \%$ & $1,1 \%$ & $4,5 \%$ & $-1,7 \%$ & $12,3 \%$ & $-17,1 \%$ & \\
\hline Industria manufacturera (IM) & $19,9 \%$ & $13,7 \%$ & $2,0 \%$ & $2,7 \%$ & $2,0 \%$ & $6,3 \%$ & $-8,0 \%$ & \\
\hline Electricidad, agua y saneamiento (EAS) & $3,3 \%$ & $2,9 \%$ & $3,4 \%$ & $4,3 \%$ & $3,2 \%$ & $22,4 \%$ & $-14,0 \%$ & \\
\hline Construcción (CONST) & $4,8 \%$ & $4,7 \%$ & $4,0 \%$ & $9,2 \%$ & $-0,03 \%$ & $21,8 \%$ & $-9,5 \%$ & \\
\hline Comercio (COM) & $11,0 \%$ & $10,3 \%$ & $3,8 \%$ & $4,1 \%$ & $3,4 \%$ & $8,6 \%$ & $-5,6 \%$ & \\
\hline Transporte, Almacenamiento (TA) & $4,0 \%$ & $4,3 \%$ & $4,7 \%$ & $5,4 \%$ & $4,1 \%$ & $8,4 \%$ & $-3,5 \%$ & \\
\hline Alojamiento y servicios de comida (ASC) & $3,2 \%$ & $3,3 \%$ & $4,4 \%$ & $5,1 \%$ & $3,9 \%$ & $11,8 \%$ & $-7,3 \%$ & \\
\hline Información y comunicaciones (IC) & $1,1 \%$ & $4,8 \%$ & $13,3 \%$ & $18,0 \%$ & $10,2 \%$ & $23,9 \%$ & $6,6 \%$ & \\
\hline Actividades financieras y de seguros (AFS) & $3,0 \%$ & $7,2 \%$ & $9,3 \%$ & $9,5 \%$ & $8,1 \%$ & $19,3 \%$ & $-0,4 \%$ & \\
\hline Actividades inmobiliarias (Al) & $8,6 \%$ & $8,3 \%$ & $4,0 \%$ & $4,7 \%$ & $3,1 \%$ & $8,4 \%$ & $0,1 \%$ & \\
\hline Actividades profesionales y servicios de apoyo (APSA) & $5,7 \%$ & $13,5 \%$ & $9,3 \%$ & $11,2 \%$ & $7,8 \%$ & $17,4 \%$ & $5,5 \%$ & \\
\hline Administración pública y seguridad social (APSS) & $6,0 \%$ & $4,1 \%$ & $2,0 \%$ & $1,6 \%$ & $1,9 \%$ & $5,5 \%$ & $0,3 \%$ & \\
\hline Enseñanza y salud humana (ESH) & $18,3 \%$ & $14,0 \%$ & $2,6 \%$ & $2,4 \%$ & $2,6 \%$ & $4,2 \%$ & $1,2 \%$ & \\
\hline Otras actividades & $3,3 \%$ & $3,3 \%$ & $4,2 \%$ & $3,7 \%$ & $4,6 \%$ & $9,1 \%$ & $-0,5 \%$ & \\
\hline
\end{tabular}

Fuente: elaboración propia con datos de la SECMCA (2019).

Es importante mencionar que las letras entre paréntesis al lado de cada actividad económica son sus iniciales, y se utilizan a manera de código para el entendimiento de otros gráficos que se mostrarán más adelante, esto por temas de espacio y mayor legibilidad. También, a modo de aclaración, el sector 
con el nombre de otras actividades incluye: actividades artísticas, de entretenimiento-recreativas, hogares como empleadores y actividades de organizaciones y órganos extraterritoriales. Además, se emplea la tasa de crecimiento anual compuesta (TCAC) ${ }^{2}$ para realizar comparaciones entre los diferentes rangos de análisis y promediar una serie de datos.

La tabla anterior ayuda a comprender las disparidades que existen entre los

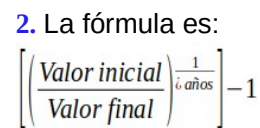
diferentes sectores productivos. Es decir, hay industrias que muestran crecimientos muy por encima del promedio total y otras que con costos logran tener una variación interanual positiva. A grandes rasgos, para el periodo comprendido entre el 2008 y 2018, la mayoría de las actividades mostraron un crecimiento menor que el periodo anterior, cuando la construcción presentó resultados negativos.

En el caso del peso relativo que tiene cada industria sobre el PIB, se puede observar que algunas han perdido participación en el 2018, en comparación con el 2000. El sector primario y de manufactura se han reducido en aproximadamente un 30\%, también la administración pública, seguridad social, la enseñanza y salud humana han presentado una caída (32\% y $24 \%$, respectivamente) en el aporte a la producción nacional. Sin embargo, existen otras que presentan todo lo contrario: un aumento significativo, por ejemplo, las actividades personales y servicios de apoyo, actividades financieras y de seguros e información y comunicaciones han aumentado su participación en este periodo a razón de 137\%, 136\% y 353\%, respectivamente.

Asimismo, el análisis anterior se puede complementar revisando las columnas sobre los montos máximos y mínimos de variación interanual, en los cuales las desigualdades se hacen más evidentes. Las industrias que más crecen lo hacen por encima del promedio total del PIB, teniendo inclusive aumentos superiores al $20 \%$ en algunos años.

La columna de la línea de tendencia permite visualizar las oscilaciones que han tenido las industrias en el periodo de análisis, así como confirmar que ninguna de las actividades económicas está mostrando una aceleración en los últimos años de la serie (3-4 años), y que, por el contrario, se observan estancamientos y desaceleraciones.

Cabe destacar, que, para tener un panorama más amplio sobre estas diferencias, se requiere de un análisis coyuntural de cada industria por separado, para así entender a profundidad las causas. No obstante, para efectos del presente trabajo, el enfoque es desde una perspectiva macro y de cómo esto limita el crecimiento económico y la generación de empleo. El gráfico 1 direcciona sobre estos temas.

Para la realización del gráfico 1 , se calcularon las tasas de crecimiento anual compuesta de cada una de las industrias del PIB en millones de colones (base 2012). Luego, se comparan las tasas de las diferentes industrias y se dividen entre el resultado del PIB (1.0x), el cual se toma como base. Esto permite entender cuánto crece una industria en relación con el crecimiento del PIB (promedio producción nacional). 
Gráfico 1. Comparación de la tasa de crecimiento compuesta anual del PIB en millones de colones por industria (2000-2018)

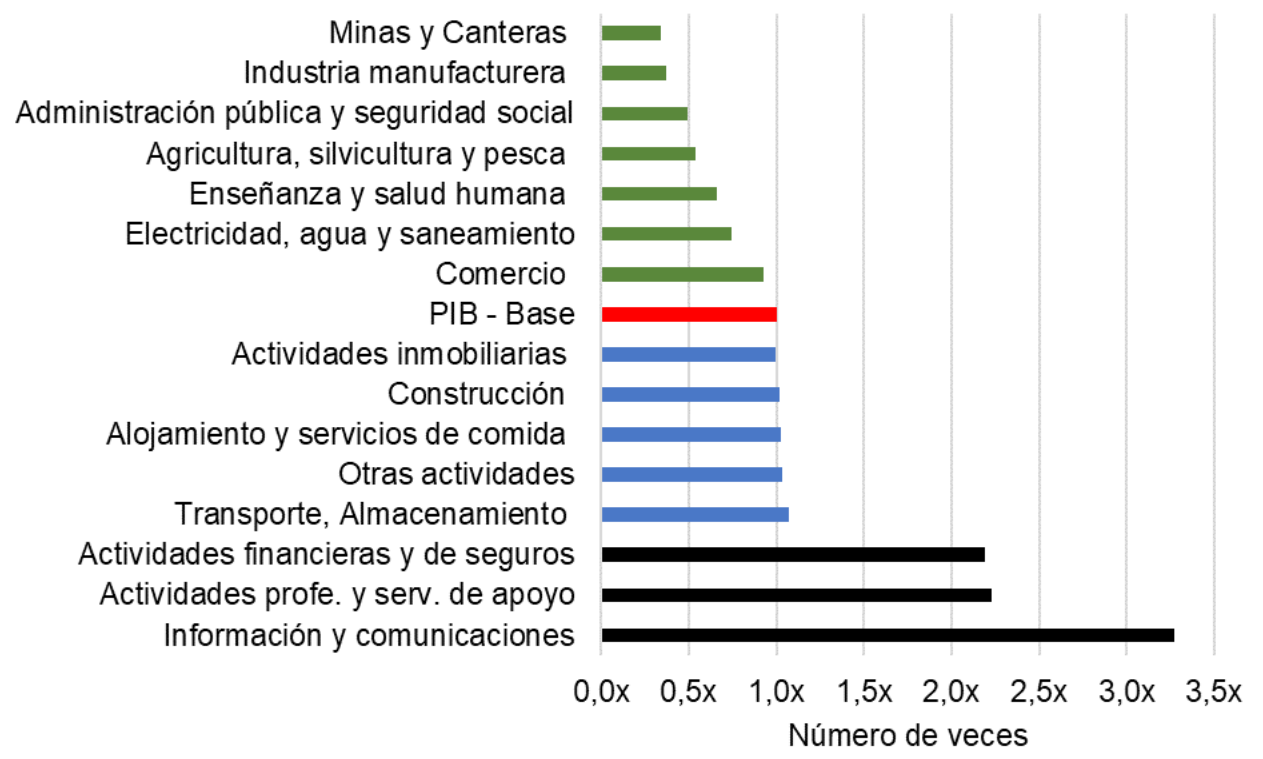

Fuente: elaboración propia con base en BCCR (2019b).

Con base en lo anterior, los resultados se agruparon en aquellas actividades económicas que más crece (negro), las que crecen similar al PIB (azul) y las que crecen por debajo (verde).

- Las de color negro representan mayoritariamente las inversiones provenientes del capital transnacional (zonas francas, centros de atención telefónica, centros de servicios compartidos, back office) y financiero (bancos privados, arrendadoras, financieras y aseguradoras), que crecen por arriba de 2.2 veces al promedio nacional de los últimos dieciocho años, donde la actividad de información y comunicaciones aumentó 3.3 veces más que el PIB. Muchas de las empresas que operan en este sector cuentan con incentivos fiscales y forman parte del impulso de las políticas económicas del Proyecto Histórico Neoliberal.

- Las de color azul han crecido de forma similar al promedio nacional. Las actividades inmobiliarias, de construcción, alojamiento y restaurantes sufrieron bastante en el periodo de la crisis financiera internacional del 2008 (caída de inversión, turismo y exportaciones) afectando su promedio. De este segmento, la que más creció fue la de transporte y almacenamiento, la cual está vinculada al comercio exterior, logística y aduanas.

- En cuanto a las de color verde, son aquellas que se han quedado rezagadas en los años en estudio, y que no han sido el foco de atención 
dentro de las políticas económicas. Algunas tienen significancia para el desarrollo del país (educación, salud, electricidad, agua y agricultura). De lo más preocupante es que estas industrias son las que más empleo masivo generan en el país; este tema se tocará más adelante.

La desigualdad en los sectores productivos se considera el segundo cortocircuito económico, ya que hace notar la poca inclusión y falta de encadenamientos entre empresas locales y las pertenecientes al sector exportador y de inversión extranjera. Asimismo, la competitividad de las industrias agrupadas en el color negro muchas veces se relaciona con incentivos fiscales, electricidad, políticas públicas, financiamiento, apoyo institucional (CINDE y PROCOMER) y capacitaciones.

De igual manera, estas disparidades de crecimiento en los sectores productivos pueden generar una carga para el resto de la economía, pues a las industrias que menos crecen les recaen el paquete de estímulos dirigidos a fomentar las exportaciones y la atracción de inversión externa de los sectores dinámicos. Es decir, la economía costarricense debe dirigir sus esfuerzos hacia un aumento de la competitividad, cambiando incentivos por eficiencia, innovación, capacitación, inversión pública y desarrollo tecnológico que permitan experimentar procesos de aceleración económica y generación de empleo. Las industrias que menos crecen son las que más empleo generan, mientras que las más dinámicas ofertan menos puestos de trabajo. El gráfico 2 lo ilustra.

\section{Gráfico 2. Relación crecimiento del PIB con generación de empleo por industria (2000-2018)}

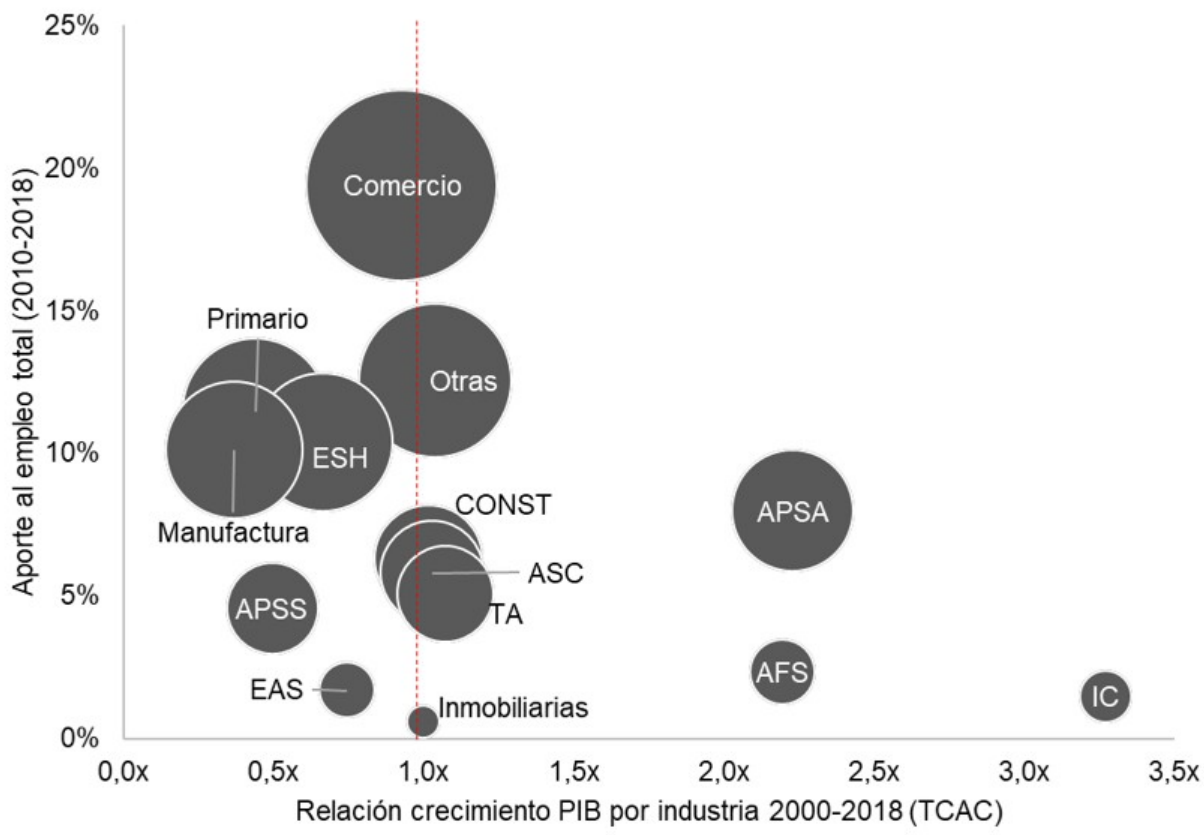

Fuente: elaboración propia con base en el BCCR (2019b) y la Encuesta Continua de Empleo (INEC 2019). 
3. El desglose es el siguiente: un $9.8 \%$ de la población desempleada tiene la primaria incompleta o menos, un $17.6 \%$ primaria completa y un $36.8 \%$ la secundaria incompleta.
Para un mejor entendimiento y acomodo del gráfico, se utilizan las abreviaciones de las industrias que al principio de este apartado se mencionaron (tabla 1).

El tercer cortocircuito económico está ligado al desempleo estructural que padece el país desde años atrás. El gráfico 2 presenta, por un lado, las burbujas con el tamaño de la generación de empleo (eje y) de cada industria durante los años comprendidos entre el 2010 y 2018, y por el otro, el crecimiento compuesto anual de cada actividad económica en relación con el promedio nacional (PIB) desde principios de siglo.

Los sectores comercio, primario, educación, salud humana y manufactura son lo que más empleos generan en el país, sin embargo, su crecimiento económico es cercano al promedio nacional o incluso por debajo de este. Contrariamente, las burbujas más pequeñas son las actividades más dinámicas de la economía. Por consiguiente, bajo este panorama es relevante traer a colación una afirmación del Vigesimosegundo Informe del Estado de la Nación:

No se puede hablar de reducciones sostenidas en la po-

breza sin poner la atención en el mercado laboral, y en

los problemas estructurales que está teniendo el país

para generar nuevos empleos y ubicar a las y los trabaja-

dores menos capacitados (Estado de la Nación 2016, 36).

La generación de empleos dignos para la mayoría de la población es un punto clave para la reducción de las desigualdades sociales y mejoras en los niveles de productividad del país. La Encuesta Continua de Empleo, publicada en febrero de 2019 (INEC 2019), sostiene que:

- Al cierre del 2018, Costa Rica registraba 293914 personas desempleadas, lo que representa un $12 \%$ del total de la fuerza laboral. El porcentaje de desempleo en las mujeres es de $14.9 \%$ y en los hombres un $10.0 \%$.

- De las personas desempleadas, el $65.6 \%$ tiene entre 15 y 34 años, el $64.2 \%$ no ha culminado la educación secundaria ${ }^{3}$ y solamente el $10 \%$ posee un título universitario.

- El trabajo informal representa el 44.9\% (971 366 trabajadores) del empleo total y un $31.9 \%$ de los trabajadores no cuenta con seguro social.

- El desempleo por región de planificación es el siguiente: 11.6\% Región Central, 12.9\% Región Chorotega, 16.6\% Pacífico Central, 13.6\% Región Brunca, 12.1\% Región Huetar Caribe y 9.6\% Región Huetar Norte. 
La relación con el cortocircuito económico se muestra al hacer referencia a que el sistema funciona mal, es decir, tenemos sectores de la economía sumamente dinámicos, pero que no generan suficientes empleos, a la vez que la población desempleada está limitada para acceder a estos por cuestiones de requisitos académicos (estudios incompletos, sin segundo idioma, poco manejo de paquetes tecnológicos) y la generación de empleo está focalizada mayormente en la Región Central, descuidando las zonas costeras y fronterizas. A lo anterior, se le suma que las actividades con mayor generación de empleo son las menos productivas y que casi la mitad del empleo ofertado en el país tiene irregularidades (sin seguro social, no se cumple el salario mínimo, jornada laboral indefinida u otras).

Existen otros factores sociales y políticos para explicar el desempleo estructural del país, sin embargo, para efectos de este trabajo solo se enfoca desde la disociación entre el crecimiento económico y la generación de empleo.

Por otro lado, se pretende analizar el nivel de endeudamiento de la población y los salarios promedio de la fuerza laboral para identificar algunas relaciones con las disparidades entre los sectores productivos y el desempleo estructural.

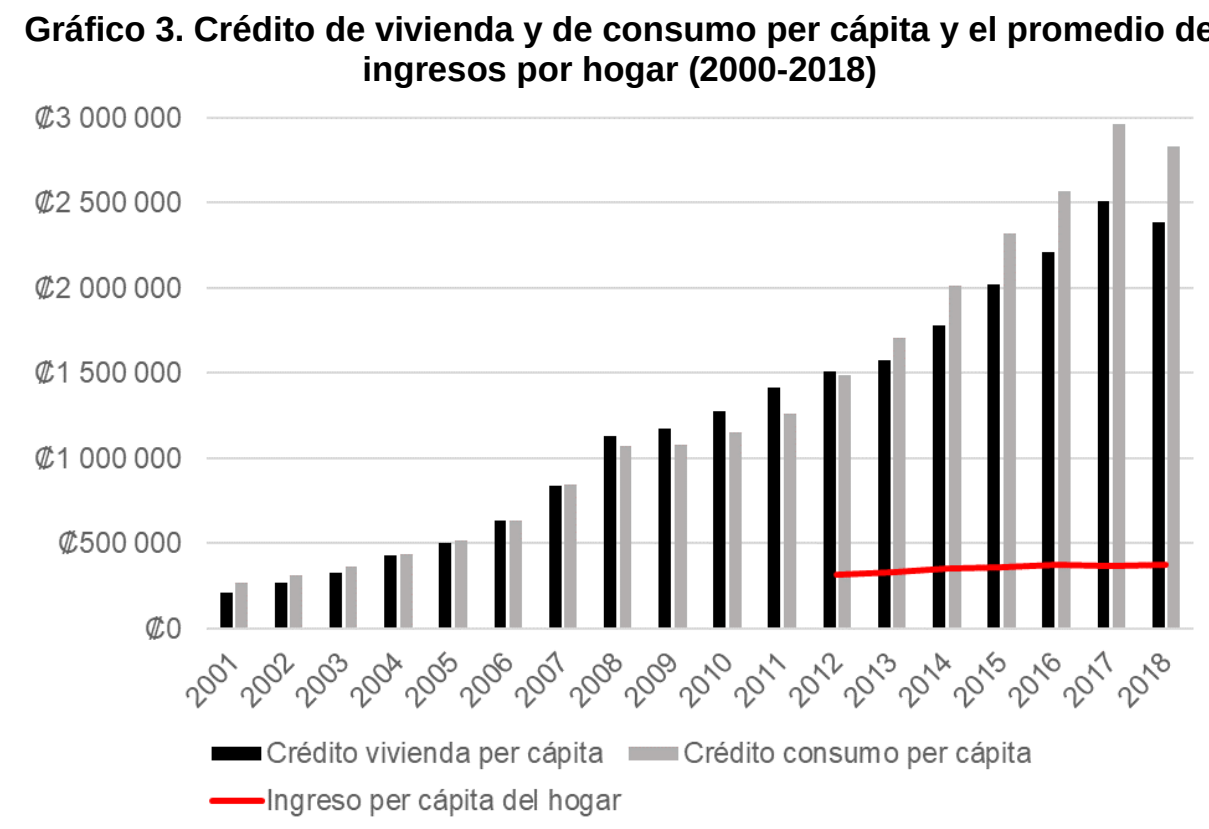

Fuente: elaboración propia con base en el BCCR (2019c) y la Encuesta Nacional de Hogares (INEC 2018).

Para la realización del gráfico, se tomaron los montos totales de las carteras de crédito (vivienda y consumo a diciembre de cada año) del sistema financiero nacional y se dividieron entre la fuerza de trabajo. Además, el ingreso 
4. Se suman los créditos otorgados del sistema financiero al sector privado no financiero por moneda (nacional y extranjera). La sumatoria incluye desde enero de 2000 hasta diciembre de 2018. per cápita del hogar contempla aquellos ingresos provenientes ya sea por el trabajo, renta de la propiedad, subsidios estatales y becas y otras transferencias (INEC 2018). Esto se utiliza para determinar el grado de endeudamiento (saldo carteras) que tiene la población en relación con sus ingresos promedio mensuales.

Las principales carteras de crédito colocadas han crecido a una tasa promedio anual durante los últimos dieciocho años de $17.4 \%$ sistema financiero nacional, $20.4 \%$ servicios, $19.4 \%$ vivienda, 19.1\% turismo, 18.8\% construcción, $18.2 \%$ consumo y $15.4 \%$ comercio (BCCR 2019c). Esto ya se podía suponer con el análisis del primer cortocircuito. Los aumentos en las diferentes actividades económicas, según el PIB, mostraban que las actividades financieras y de seguros se encuentran dentro de las más dinámicas.

Los préstamos colocados por actividad económica entre el total del sistema financiero arrojan que, para el año 2000 , el $20.2 \%$ se dirigió hacia vivienda, $28.8 \%$ a consumo, $15.1 \%$ a comercio, $8.2 \%$ a servicios, $12.8 \%$ a industria y $6.5 \%$ a agricultura. Mientras que, para el 2018, los datos cambian a $27.7 \%$ vivienda, $32.9 \%$ consumo, $11.2 \%$ comercio, $13.1 \%$ servicios, $3.7 \%$ industria y 2.1\% agricultura (BCCR 2019c). Esta información denota el enfoque dirigido por la banca en la colocación de créditos, siendo vivienda y consumo los más representativos (más del 60\% al 2018).

Otro factor por considerar es la evolución del crédito por moneda, ya que existe una diferencia relevante. Al tomar el acumulado ${ }^{4}$ de préstamos, se observa que los bancos públicos han colocado un $68.3 \%$ de sus créditos en moneda nacional (colones) y un $31.7 \%$ en moneda extranjera (dólares, principalmente). Para los bancos privados se invierte la proporción, un $24.4 \%$ en moneda local y un $75.6 \%$ en moneda extranjera. Asimismo, de la totalidad de préstamos colocados en moneda extranjera, el $61.4 \%$ ha sido por la banca privada. A esto habría que sumarle que la mayoría de las familias en el país no son generadoras de dólares, creando mayor vulnerabilidad debido a los cambios que puedan surgir en cuanto al tipo de cambio con esta moneda.

Esta información nos dirige hacia el cuarto cortocircuito económico relacionado con el endeudamiento de la población. Como se puede observar en el gráfico 3, en el 2012 la población tenía un endeudamiento de consumo de 10.4 veces sus ingresos mensuales y para el 2018 este dato pasó a 18.8 veces. Además, es de suma importancia mencionar que la cartera de consumo aquí analizada no incluye los datos sobre préstamos del comercio no regulado, tales como los otorgados por Gollo, Monge, Beto te Presta, Instacredit, entre otras (la información no es pública). Si estos datos se incorporaran, las cifras serían mucho más desastrosas. Esto es parte de la realidad que está enfrentando la mayoría de las familias en el país, principalmente la clase media trabajadora.

Los cambios estructurales en la economía costarricense iniciados en la década de los ochenta, marcan el inicio de un cambio en la forma de consumo de la población, ya que conforme se ha ido consolidando la banca privada, las personas han empezado a tener acceso a una serie de productos financieros 
(tarjetas de crédito, leasing, préstamos personales, hipotecas, etc.) para realizar sus compras (artículos del hogar, vehículos, viajes, alimentación), esto con una nula educación financiera sobre cómo utilizarlos. Es así como:

La hegemonía pasa a manos de las finanzas, y ello desde varias perspectivas concomitantes: por el peso de los flujos de capitales y su decisiva influencia en el devenir de la economía costarricense; por las ventajas que en ese contexto obtiene la banca y, en general, el negocio financiero; por la incrementada capacidad que esta última desarrolla para alimentar su ganancia por medio de la extracción de rentas provenientes del endeudamiento incrementado de empresas productivas y familias (Vargas Solís 2015, 155).

Lo anterior es un tema que da para mucha discusión y se debe estudiar a profundidad para entender las vulnerabilidades que está generando el endeudamiento de las familias, así como lo relacionado con los préstamos a empresas nacionales (pymes). Además, esto se puede conectar con los otros cortocircuitos anteriormente expuestos, ya que nos puede guiar sobre el entendimiento de las desigualdades en las actividades productivas, la hegemonía de los GPE, la banca transnacional y las políticas económicas en general.

\section{Gráfico 4. Comparación de cifras fiscales con respecto al PIB a precios corrientes (2008-2018)}

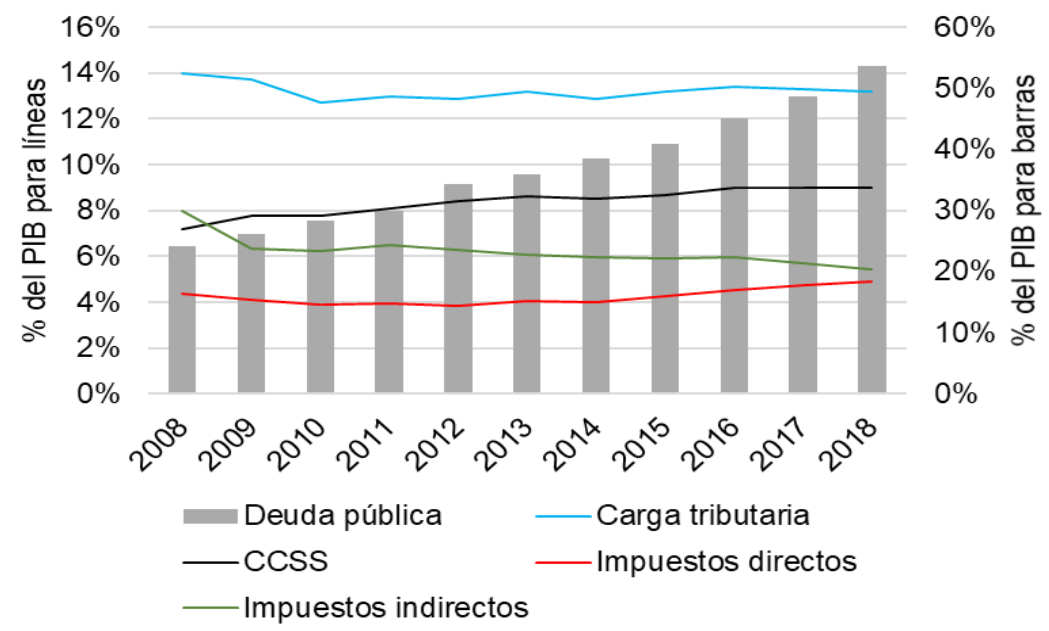

Fuente: elaboración propia con base en el Ministerio de Hacienda y el Instituto Centroamericano de Estudios Fiscales (ICEFI 2019). 
Otro tema trascendental sobre los problemas estructurales que enfrenta la economía es acerca del ajuste fiscal necesario para solventar la crisis en las finanzas públicas del Gobierno Central.

La carga tributaria es el total de impuestos que recauda el Gobierno Central sin tomar en cuenta la seguridad social, la cual se separa para visualizarla mejor, pero que, en conjunto, estas dos cuentas forman lo que se conoce como la presión fiscal. Además, los impuestos directos se calculan con el impuesto sobre la renta cobrado y los indirectos incluye el impuesto general de ventas, consumo e importaciones; todos estos datos en relación con el PIB para su comparabilidad.

Las finanzas públicas enfrentan desafíos estructurales que, en primera instancia, se relacionan con el gasto público, siendo este insuficiente y rígido para hacer frente a las demandas de la sociedad, en donde cada vez más una porción de este se destina al pago del servicio de la deuda. También, existe poca transparencia en su ejecución, imposibilitando la eficiencia en el uso de los recursos (ICEFI 2019).

Por el lado de los ingresos, se empieza porque estos son limitados para cubrir los gastos, la carga tributaria se ha mantenido casi estática durante los últimos dieciocho años (en el 2000 era $12.7 \%$ y en el $2018,12.5 \%$ del PIB), sigue persistiendo el incumplimiento tributario, ya que, de acuerdo con el FMI, al 2015 el impuesto de renta se incumplía en un 59.6\% y el impuesto general de ventas en un 31.1\%. Entonces, sigue la evasión y elusión fiscal, además de que el sistema tributario no permite el combate eficiente contra los flujos ilícitos de capital (ICEFI 2019).

A lo anterior, se le suma que la deuda pública viene creciendo de manera sostenida y que en los último diez años se ha duplicado, pasando de $24.1 \%$ del PIB en el 2008 a un 53.6\% en el 2018.

La raíz del problema tiene que ver con la erosión paulatina que se ha generado en la base tributaria del Estado, muy relacionado con la estrategia de desarrollo marcada desde finales del siglo pasado. Los grandes capitales y sectores más acaudalados cuentan con un abanico de opciones para evadir o eludir impuestos, al mismo tiempo que la administración tributaria no ha desarrollado las competencias necesarias y que esta incapacidad les favorece a estos sectores (Vargas Solís 2015). La ineficiencia del sector público se puede entender desde dos puntos de vista, como lo muestra la próxima cita:

Esto significa, por ejemplo, que no debe enfocarse en cómo las prácticas de los grupos empresariales reflejan las debilidades de las instituciones locales, sino también en cómo pueden potencialmente contribuir a mantener esas debilidades a través de sus prácticas e influencia política (Bull y Kasahara 2017, 41). 
Es evidente como la falta de herramientas legales y tecnología en la administración tributaria del país ha favorecido las estrategias de planificación fiscal que ejecutan algunos GPE, en donde las debilidades del Ministerio de Hacienda, en cuanto a fiscalización, han potenciado la consolidación de una "cultura" de evasión y elusión de impuestos que ha sido normalizada por las élites empresariales.

En las discusiones en torno al déficit fiscal surgen contradicciones, ya que, por un lado, el gasto público social (asistencia, educación, etc.) se resiste a decrecer, y por el otro lado, los profesionales liberales y empresas se rebelan contra la tributación. Además, a lo largo de los años, los impuestos directos se han reemplazado por más deuda y se ha dado un estancamiento de la presión fiscal, volviéndose inaceptable la tesis de que la evasión y elusión fiscal se genera ante una alta o excesiva carga tributaria. En las últimas décadas, se han desarrollado las técnicas más sofisticadas para la erosión de la base imponible (López Garrido 2016).

Ahora bien, siguiendo con los problemas estructurales en las finanzas públicas, el ICEFI (2019) sostiene que la estructura tributaria es regresiva, la cual se carga más sobre los impuestos indirectos, tal cual lo muestra el gráfico 4. Al cierre del 2018 , el $59 \%$ de los ingresos tributarios provenían de los indirectos.

Asimismo, se sostiene que, para atender estos desafíos estructurales, el país debe alcanzar un gasto público de $28.6 \%$ del PIB en 2030 , se debe financiar el incremento del gasto social y es necesario mejorar los mecanismos de transparencia institucional y manejo de presupuestos. De igual manera, se requiere de una modernización de la estructura tributaria, incorporando el principio de renta mundial, así como una implementación de prácticas internacionales para reducir la evasión y elusión de impuestos, y detener la estrategia de otorgamiento de incentivos tributarios de largo plazo (ICEFI 2019).

Los problemas aquí expuestos forman parte de una serie de limitantes que tiene el país y que generan un ensanchamiento de las desigualdades socioeconómicas. Las políticas y el pensamiento económico que han dominado durante las últimas cuatro décadas nos muestran una polarización. Grandes ganadores con niveles altos de productividad y crecimiento, acceso a puestos clave en el Gobierno para cubrir sus intereses, en algunos casos han basado sus ganancias en la extracción de rentas proveniente del endeudamiento de familias y poseen un abanico de opciones que, con apoyo de asesores (financieros, contables, tributarios, legales, etc.), logran proteger sus capitales de las autoridades fiscalizadoras; al mismo tiempo que el desempleo se agudiza, la clase media se endeuda para consumir, la inversión pública es insuficiente y la pobreza se sostiene en gran parte por el gasto social, el cual pretende ser sometido a las rigurosidades de la austeridad propuestas por organismos internacionales. 


\section{Conclusiones}

El trabajo permite identificar cinco cortocircuitos económicos que se han agudizado conforme pasa el siglo XXI y se resumen de la siguiente forma:

1. La hegemonía en el pensamiento económico ha moldeado las políticas en torno al estilo de desarrollo, las propuestas para enfrentar los problemas estructurales y ha reducido el espacio para propuestas alternativas. Esto a través de las redes de poder y vinculación entre GPE, tanques de pensamiento y puestos en gabinetes.

2. Las desigualdades en los sectores productivos generan cargas sobre algunas actividades económicas, producto de las políticas de estímulo para fomentar otras. La baja productividad, innovación y desarrollo tecnológico de la economía local hace que el crecimiento sea insuficiente para proporcionar mejores oportunidades para la población.

3. El desempleo estructural muestra el descalce entre el crecimiento económico y la generación de empleo, lo cual es necesario revertir para reducir la pobreza y ubicar a las y los trabajadores menos capacitados.

4. El endeudamiento de la población refleja una triste realidad, la generación de riqueza de algunos sectores proviene del sobreendeudamiento de las personas con menos recursos y educación. La usura se ha vuelto un buen negocio para ciertos sectores empresariales en la región de Centroamérica.

5. El sistema de impuestos en Costa Rica se ha caracterizado por desarrollar una estructura tributaria regresiva y con cierta permisividad para las prácticas de evasión y elusión, lo cual dificulta hacer frente a muchas de las demandas de la sociedad e inversión pública; al mismo tiempo que las prácticas de planificación fiscal agresiva se han ido consolidando en las empresas multinacionales y regionales.

Estos cortocircuitos ponen luz a la crisis que está viviendo el estilo de desarrollo económico en la actualidad, en el cual muchas de las políticas ejecutadas han llevado a agudizar las desigualdades, y ponen en duda cuál será el rumbo del país si se continúa con la misma receta de hace cuarenta años. Cabe mencionar que estos no son los únicos problemas que acechan la economía, pero sí una base para iniciar discusiones acerca de las ideas y propuestas dominantes, así como la búsqueda de alternativas desligadas de los GPE.

Lizano Fait (2010) menciona que estamos ante una "superposición de modelos" que no permiten el debido desarrollo de la liberalización económica, ya que aún se mantienen elementos del "viejo modelo", refriéndose a los monopolios estatales controlados por sindicatos, proteccionismo arancelario, una excesiva tramitología, entre otros. Pero, por otro lado, Vargas Solís (2015) sostiene que el PHN está sumamente debilitado y cuestiona su viabilidad futura, debido al atraso en inversión pública, educación, ciencia y tecnología, 
así como las graves "deformaciones y desbalances" de la estructura productiva.

\section{Bibliografía}

Academia de Centroamérica. 2019. «¿Quiénes somos? Lista de asociados».

Acceso el 24 de enero. https://goo.gl/7QaAT8

Banco Central de Costa Rica (BCCR). 2019. «Programas Macroeconómicos». Acceso el 7 de febrero. https://goo.gl/zQZeau

Banco Central de Costa Rica (BCCR). 2019b. «Producto Interno Bruto por Actividad Económica: Volumen a precios del año anterior encadenado, referencia 2012». Acceso el 7 de febrero. https://bit.ly/2XgolYY

Banco Central de Costa Rica (BCCR). 2019c. «Crédito del sistema financiero al sector privado por actividad económica». Acceso el 7 de febrero. https://goo.gl/XKRJ8v

Blanco Lizano, Randall. 2010. «Partidos políticos, redes corporativas y formación de gabinetes en Costa Rica: 1986-2010». Revista de Ciencias Sociales 4(130): 161-172.

Blanco Lizano, Randall. 2011. «Rentismo y modelo liberalizador en Costa Rica. El caso de la Fundación Omar Dengo: 1987-2009». Revista Electrónica de Historia 12(1): 35-51.

Blanco Lizano, Randall. 2012. «Campos, relaciones y redes de poder: debates teóricos para la comprensión de las disputas por el control del Estado». Revista Reflexiones/Jornadas de Investigación Interdisciplinaria: 95-106. doi: 10.15517/rr.v0i0.1526.

Bull, Benedicte, Fulvio Castellacci y Yuri Kasahara. 2014. Business Groups and Transnational Capitalism in Central America. London: Palgrave Macmillan.

Bull, Benedicte y Yuri Kasahara. 2017. «La transnacionalización de los grupos empresariales diversificados y el rostro cambiante de las élites económicas de Centroamérica». Anuario de Estudios Centroamericanos 43(1): 37-69. 
Consejeros Económicos y Financieros S.A. (CEFSA). 2013. «Equipo de trabajo». Acceso el 24 de enero de 2019. https://goo.gl/2ZnJ9S

Consejo Nacional de Supervisión del Sistema Financiero (CONASSIF). 2018. «CONASSIF nombra Superintendente General de Entidades Financieras». Acceso el 7 de febrero de 2019. https://goo.gl/EtDpZ7

Cuestamoras. 2019. «Alberto Trejos segundo vicepresidente de la Junta Directiva y director externo». Acceso el 7 de febrero. https://goo.gl/KcMzEJ

Deloitte Touche Tohmatsu Limited. 2019. «Nuestros líderes». Acceso el 24 de enero. https://goo.gl/z42LMT

Ecoanálisis Consultores Económicos y Financieros (Ecoanálisis). 2019. «Socios Consultores Ecoanálisis». Acceso el 10 de febrero. https://goo.gl/ydbepw

Escalante Gonzalbo, Fernando. 2015. Historia mínima del neoliberalismo. Ciudad de México: El Colegio de México.

Estado de la Nación. 2016. Vigesimosegundo Informe Estado de la Nación en desarrollo humano sostenible. San José: Programa Estado de la Nación. https://goo.gl/mVrqHS

Ferrari, Marcela. 2010. «Prosopografía e historia política. Una aproximación». Antíteses 3(5): 529-550.

Grupo Aldesa. 2019. «Información Corporativa, Junta Directiva». Acceso el 7 de febrero. https://goo.gl/4zPXfg

Strachan, Harry. 2017. «About Harry». Acceso el 7 de febrero de 2019. https://goo.gl/ps2Xr9

Hidalgo Bogantes, Juan. (2013, abril 8). «Las confesiones del presidente del Banco Central». El Financiero. Acceso el 24 de enero del 2019. https:// goo.gl/ar4mUi

Instituto Centroamericano de Estudios Fiscales (ICEFI). 2019. «Desafíos fiscales estructurales de Costa Rica: más allá de la reforma fiscal de 2018». Conferencia pronunciada en la Asamblea Legislativa de Costa Rica, 7 de febrero. https://goo.gl/Ay991r 
Instituto Centroamericano de Administración de Empresas (INCAE). 2013. «INCAE 50 aniversario, línea de tiempo». Acceso el 7 de febrero de 2019. https://goo.gl/ZynGgS

Instituto Nacional de Estadísticas y Censos de Costa Rica (INEC). 2018. «Encuesta Nacional de Hogares». Acceso el 12 de febrero de 2019. https://goo.gl/oLvReL

Instituto Nacional de Estadísticas y Censos de Costa Rica (INEC). 2019. «Encuesta Continua de Empleo». Acceso el 12 de febrero. https://goo.gl/f4TPh2

Leitón, Patricia y Esteban Ramírez. (2018, abril 26). «Rodrigo Cubero: economista dejará alto cargo en FMI para tomar las riendas del Banco Central». La Nación. Acceso el 7 de febrero de 2019. https://goo.gl/nVqP62

Lizano Fait, Eduardo. 2010. Acerca del “¿qué?” y del “¿cómo?”. San José: Academia de Centroamérica, 2010.

López Garrido, Diego. 2016. Paraísos fiscales. 20 propuestas para acabar con la gran evasión. Madrid: Los libros de la catarata.

Ministerio de Economía, Industria y Comercio de Costa Rica (MEIC). 2015. «Exjerarcas del Ministerio de Economía, Industria y Comercio 18822015». Acceso el 24 de enero de 2019. https://goo.gl/HjDzL1

Mesoamerica Investments. 2019. «About the firm». Acceso el 24 de enero. https://goo.gl/g2J762

Pérez Brignoli, Héctor. 2018. Historia global de América Latina. Madrid: Alianza Editorial.

Porras Jara, Carlos. 2010. Los primeros cien años de Florida Ice \& Farm. San José: FIFCO.

Pozas Garza, María de los Ángeles, Minor Mora Salas y Juan Pérez Sáinz. 2004. La sociología económica: una lectura desde América Latina. San José: Facultad Latinoamericana de Ciencias Sociales.

Robles Rivera, Francisco. 2016. «Fotografía de la Familia: ¿Quiénes son y cómo son los Grupo de Poder Económico en Costa Rica? 1948-2014». En Historia de las desigualdades sociales en América Central, editado 
por Ronny J. Viales Hurtado y David Díaz Arias, 173-194. San José: CIHAC.

Robles Rivera, Francisco. 2011. «Los de entonces ya no son los mismos. Acumulación por desposesión en la última década en El Salvador y Costa Rica». Anuario de Estudios Centroamericanos 37(1): 105-137.

Robles Rivera, Francisco. 2014. «Transformaciones y concentración en grupos de poder económico en Costa Rica (1980-2012)». Revista Mexicana de Sociología 76(1): 37-58.

Secretaría Ejecutiva de Consejo Monetario Centroamericano (SECMCA). 2019. «Estadísticas históricas». Acceso el 24 de enero. http://www.secmca.org/EH.html

Superintendencia General de Entidades Financieras (SUGEF). 2016. «Principales puestos por dependencia». Acceso el 24 de enero de 2019. https://goo.gl/nAdWT7

Vargas Solís, Luis. 2005. «Globalización y políticas económicas: mecanismos de determinación y condicionamiento. El caso de Costa Rica 19842010». Tesis doctoral. Universidad de Costa Rica.

Vargas Solís, Luis. 2006. Entre la vida y el mercado: Tratado de Libre comercio Estados Unidos-Centroamérica-República Dominicana (TLCEUCARD). San José: EUNED.

Vargas Solís, Luis. 2015. «El Proyecto Histórico Neoliberal en Costa Rica (1984-2015): devenir histórico y crisis». Revista Rupturas 6(1): 147162. 